J. Lake Sci. (湖泊科学), 2016, 28(3): 676-681

DOI 10. 18307/2016. 0325

(C) 2016 by Journal of Lake Sciences

\title{
1950s 以来洞庭湖调蓄特征及变化
}

\author{
黄 群,孙占东,赖锡军,姜加虎 \\ (中国科学院南京地理与湖泊研究所湖泊与环境国家重点实验室,南京 210008)
}

\begin{abstract}
摘 要: 针对洞庭湖区淤积、围庢和江湖关系变化对湖泊调蓄功能的影响, 根据洞庭湖调蓄属于典型复合洪水波的实际 情况, 提出利用离散小波分解和计算人、出湖径流过程方差的方法揭示 $1950 \mathrm{~s}$ 以来洞庭湖调蓄特征及其实际调蓄作用的 多年变化. 结果发现: 洞庭湖削减的洪峰主要是 $32 \mathrm{~d}$ 以下的中短尺度洪水波, 其全年整体削峰系数在 $0.13 \sim 0.56$ 之间; 从 人、出湖径流方差多年变化体现的调蓄效果看, 洞庭湖区近几十年淤积围层虽然极大地改变了湖区面积和容积, 但并未 使湖泊调蓄作用发生大的变化. 结合洞庭湖削峰系数与城陵矶-螺山段水位落差的对应关系, 认为在整个江湖系统关系中 洞庭湖的调蓄能力是被动的,其变化主要取决于城陵矶以下河段过水能力对洞庭湖泄流的制约. 从整个江湖关系下的洞 庭湖调蓄变化特征看, 1990s 以来湖区 “小水大灾” 的原因之一是人湖径流过程的短尺度方差和削峰系数较大, 本质上是 由荆江裁弯和三峡运行导致的江湖关系变化引起的长江螺山段出流使出湖径流方差减小造成的.
\end{abstract}

关键词: 湖泊调蓄作用;洞庭湖; 小波分析;方差变化;江湖关系

\section{Changes of the flood regulation capacity at Lake Dongting since 1950s}

\section{HUANG Qun, SUN Zhandong, LAI Xijun \& JIANG Jiahu}

(State Key Laboratory of Lake Science and Environment, Nanjing Institute of Geography and Limnology, Chinese Academy of Sciences, Nanjing 210008, P.R.China)

\begin{abstract}
In view of flood regulation capacity at Lake Dongting affected by reclamation, deposition and change of lake-river relationship, the characterization, mechanism and impact of the flood regulation capacity since 1950 s were analyzed by using methods of wavelet decomposition and corresponding standard deviation amplitude. The results indicated that the flood regulation of the lake is mainly functioned on the high frequency foods with an average flood peak removing coefficient between 0.13-0.56. Although reclamation and deposition had largely decreased the water storage capacity of Lake Dongting, the flood regulation capacity did not change much revealed by the difference of standard deviation between inflow and outflow in a long term. The area and water storage capacity are only static parameters for the capacity of flood regulation at Lake Dongting. In term of the perspective of lake-river relationship, the dynamic of flood regulation capacity was mainly affected by the stage-discharge relation at the outlet of the lake, which is decided by the river channel morphology. The major reason for the phenomenon of "normal discharge but high water level" can be explained by the high standard deviation of inflow and the big flood peak removing coefficient, essentially resulting from the decrease of discharge deviation in the Luoshan channel of the Yangtze River which was caused by the channel straightening in the downstream of the Three Gorges.
\end{abstract}

Keywords: Flood regulation; Lake Dongting; wavelet decomposition; standard deviation; lake-river relationship

大型外流吞吐湖因蓄水量大,可显著坦化和滞后汛期人湖洪峰流量·湖泊调节河川径流的功能主要表 现在对人湖洪峰的调蓄, 减轻下游洪水威胁. 由于湖泊出口与河道自由连通,湖泊对洪水的调蓄显著区别于 水库, 其调蓄总量和滞时作用处在不断的动态变化中. 这个动态变化过程除了与湖泊自身特征有关外, 湖泊 出口与下游河道连接关系决定的出流特征是重要影响因素.

* 国家重点基础研究发展计划“973” 项目 (2012CB417003)、中国科学院学科前沿和交叉项目 ( NIGLAS2012135018) 和科技基础性工作专项 (2012FY111800-03) 联合资助. 2015-03-05 收稿;2015-09-14 收修改稿. 黄群( 1964 ), 男,副研究员;E-mail:qhuang@ niglas.ac.cn. 
洞庭湖由于调蓄容量巨大, 对长江中游的防洪有着举足轻重的作用. 其对长江和流域人湖洪水多年平 均削峰量达 30\% 左右. 1954 年特大洪水期间, 削减洪峰流量 $27400 \mathrm{~m}^{3} / \mathrm{s}$, 占洪峰量的 $40 \%$, 滞后洪峰 3 日, 极 大地减轻了长江干流的洪水压力. 随着湖区大范围的围垦活动和剧烈的泥沙淤积, 湖泊容积急剧减少 ${ }^{[1-6]}$. 洞庭湖蓄水量由解放初的近 $300 \times 10^{8} \mathrm{~m}^{3}$ 下降到目前的 $174 \times 10^{8} \mathrm{~m}^{3}$. 湖区这些变化及其对湖泊调蓄削峰能力 的影响受到广泛关注,尤其针对洞庭湖 1990s 以来不断加剧的“小水大灾” 现象及其与湖泊调蓄关系, 在认 识上存在诸多争议 ${ }^{[7-8]}$. 代表性分析结论包括: 淤积、围旺导致的湖泊容积减少使湖泊调蓄能力降低, 进而导 致洪灾加剧; 基于湖盆变化的水文分析认为淤积、围旺非近年洪灾加剧的主要因素; 而一日调蓄量则反映 $1950 \mathrm{~s}$ 以来洞庭湖调蓄量增大现象 ${ }^{[3-5,9]}$. 这些分析从不同侧面揭示了洞庭湖变化对湖泊调蓄能力的可能影 响, 但在湖泊调蓄与水库调蓄的差异、洞庭湖与长江的复杂关系, 以及同水位级别出口流量减少等方面存在 不足.

湖泊调蓄的结果使得出湖径流过程变得平缓, 故可通过对比人、出湖径流过程长期差异以反映洞庭湖 的调蓄作用实际变化. 本次研究根据洞庭湖洪水波的实际过程是由若干不同波长的子波叠加而成, 提出利 用离散小波分解, 并计算人、出湖径流过程方差的方法, 在考虑到江湖关系变化格局条件下揭示洞庭湖调蓄 特征及其实际调蓄作用的多年变化.

\section{1 数据和方法}

\section{1 研究区概况}

洞庭湖 $\left(28^{\circ} 44^{\prime} \sim 29^{\circ} 35^{\prime} \mathrm{N}, 111^{\circ} 53^{\prime} \sim 113^{\circ} 5^{\prime} \mathrm{E}\right.$ ) 位于荆江南岸, 湖区来水主要由长江“三口” (松 滋、太平、藕池) 和洞庭湖水系湘江、资水、沅水和 澧水“四水”构成, 这些人流经过洞庭湖调蓄后由 城陵矶再次汇人长江干流. 其中, 长江的洪水主 汛期为 7、8 月份, “四水” 的汛期一般为 4-9 月. 每年汛期湘、资水先涨水, 提升湖泊底水位, 沅、 澧水后涨, 进一步提高湖水位, 随之而来的长江 洪水自 “三口” 人湖, 进一步抬高洪水位. 作为中 国历史上最大的淡水湖, 洞庭湖面积一度超过 $6200 \mathrm{~km}^{2}$ (1825 年), 随后, 由于泥沙淤积和垦殖, 面积减少到 1949 年的 $4350 \mathrm{~km}^{2}$, 自 1950s 开始的 大规模围湖造田使得湖泊面积进一步缩减到目 前的 $2625 \mathrm{~km}^{2}$ (图 1). 湖区水情随着季节性水文 节律呈现 “洪水一大片, 枯水几条线” 典型通江调 蓄湖泊水情特征. 相对于长江干流, 洞庭湖对洪 水的调蓄作用非常显著, 作为长江中游重要的调 蓄湖泊, 对整个长江中游的防洪有着举足轻重的

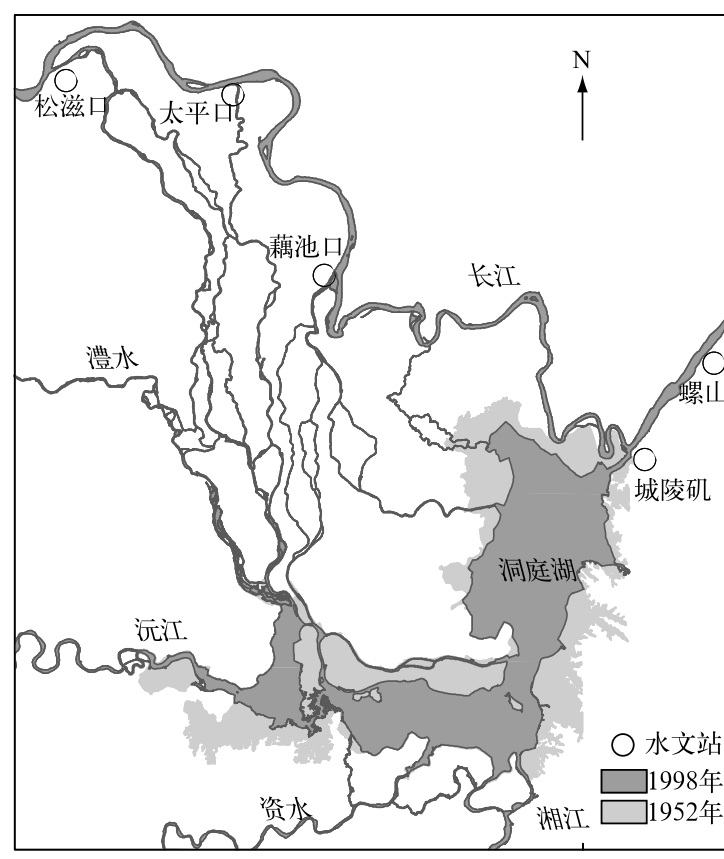

图 1 洞庭湖区水系及面积演变

Fig. 1 Stream networks and the evolution of Lake Dongting 作用 ${ }^{[2-3,6,6,10]}$.

\section{2 数据和方法}

洞庭湖对洪峰的调蓄能力是特定时段内调蓄水位及其对应水面的函数 $f_{t}(S, \Delta l)$, 其中 $S$ 在一定时期基 本固定 (近似于最大水面面积), 而 $\Delta l$ 的决定因素是复杂江湖关系条件下的江湖顶托、遭遇和过流能力, 并 与时段 $t$ 长短关系密切. 也就是说江湖关系直接影响湖泊自身的调节作用. 因此, 洞庭湖调蓄能力的分析需 要在考虑江湖关系前提下, 分时段进行.

湖泊对洪水调蓄的最根本体现是对人、出湖洪峰波形的改变, 在调蓄量的度量上, 单次洪峰调蓄以人流 最大洪峰与出流洪峰值的差值表示削峰量, 该指标适用于中小湖泊、水库的洪水调蓄. 而洞庭湖区的洪峰调 蓄属于典型的复合洪水调蓄, 洪水的削峰量受洪水量级、洪水峰型、洪峰组合以及起调水位等许多因素的影 
响,一般每次都不可能相同. 针对洞庭湖人流为复杂复合洪水的情况, 首先利用小波分解技术将人、出湖洪 水过程分解成若干不同周期长度的子洪水波的组合 ${ }^{[11-12]}$, 同时以流量过程方差比较代替流量的直接比较, 来量化洞庭湖对不同类型洪水调蓄作用的差异, 在此基础上利用中短尺度子波方差及湖泊削峰系数变化分 析洞庭湖实际调蓄作用的多年变化. 分析数据包括: 湖区 1950s 以来不同时期湖盆地形图, 洞庭湖流域“四 水”、长江“三口”、城陵矶以及螺山的逐日径流.

\section{2 结果与分析}

洞庭湖实际洪水过程是由若干不同波长的子洪水波叠加而成, 对其分解可以从不同尺度上揭示洞庭湖 对洪水的调蓄特征. 从典型洪水年份 1998 年人、出流 sym6 小波分解对比 (图 2) 可以看出, 洞庭湖人、出流过 程的高频波动差别显著; 而人、出流过程五级分解后的低频部分几乎一致. 从调蓄效果上看, 洞庭湖对洪水 过程的调节作用类似于一个低通滤波器, 人湖洪水波的高频波动经湖泊调蓄后被显著平滑. 其中 “三口” 和 “四水” 人湖单次 $1-3$ 日洪峰几乎被洞庭湖完全削减, 洞庭湖对不同洪水平滑能力随周期延长而逐渐出现 差异, 对 5 级以上洪水波调蓄能力已十分微弱.
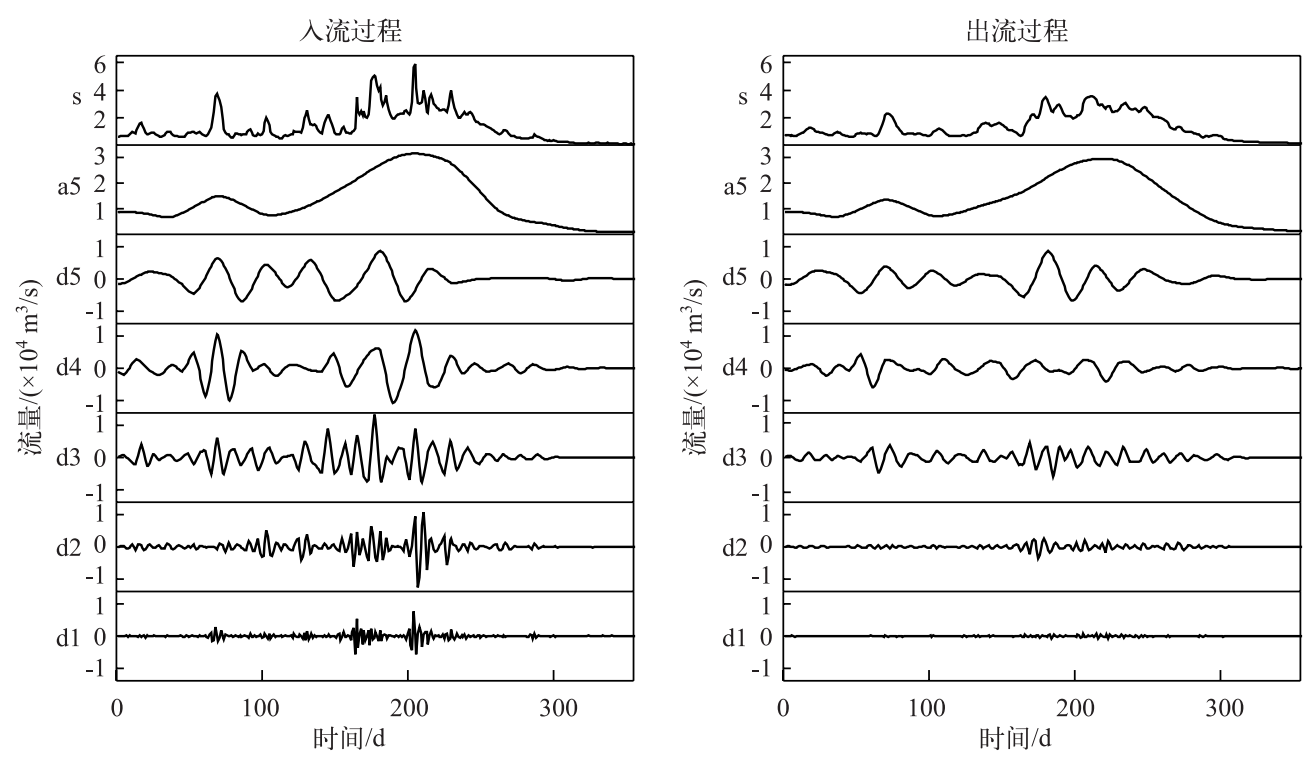

图 21998 年人、出流小波分解对比

Fig.2 The wavelet decomposition for inflow and outflow of the lake in 1998

在对洞庭湖人出流小波分解基础上, 统计了不同波长的方差差异 (图 3). 从洞庭湖多年人、出流小波分 解各级方差比较可以看出, 人湖径流经过洞庭湖调蓄之后, 方差大幅度下降; 洞庭湖对径流过程波动的削减 作用随波动历时的加长而减弱, 起作用的主要是 $32 \mathrm{~d}$ 以下的波动 ( $1 \sim 5$ 级). $1 、 2 、 3$ 级子波方差削减率分别 达 $66.7 \% 、 64.2 \%$ 和 $47.7 \%$, 对应时间周期为 $2 、 4$ 和 $8 \mathrm{~d}$, 而 4 级 $16 \mathrm{~d}$ 周期洪水波削减率为 $29.2 \%, 32 \mathrm{~d}$ 级别削 减率降为 $20.1 \%$.

从洞庭湖对中短尺度洪水波削峰系数多年过程 (图 4) 可以看出, 洞庭湖对入湖洪水全年的削峰系数在 0.13 0.56 之间,多年平均值在 0.30 左右,总体来看对洪峰的削减作用非常显著.

从洞庭湖多年人、出流中短尺度方差变化 (图 5) 可以看出, 出湖径流的中短尺度方差多年变化比较平 稳, 说明虽然洞庭湖湖盆形态变化巨大 (图 1), 但洞庭湖对径流的实际调蓄作用多年来并未发生大的变化. 而削峰系数的多年变化与人流方差较为一致, 即人流方差越大, 调蓄作用越大, 也就是人湖流量越大, 洞庭 湖能够调蓄的水量越大. 从洞庭湖中短尺度人、出流方差的多年变化分析可以看出, 无明显年代分异现象, 说明洞庭湖调蓄作用大小随人湖洪水特性差异而变化, 但是不存在系统性变化或突变, 即便在大规模围垦 
后的 $1980 \mathrm{~s}-1990 \mathrm{~s}$ 亦无衰减迹象.

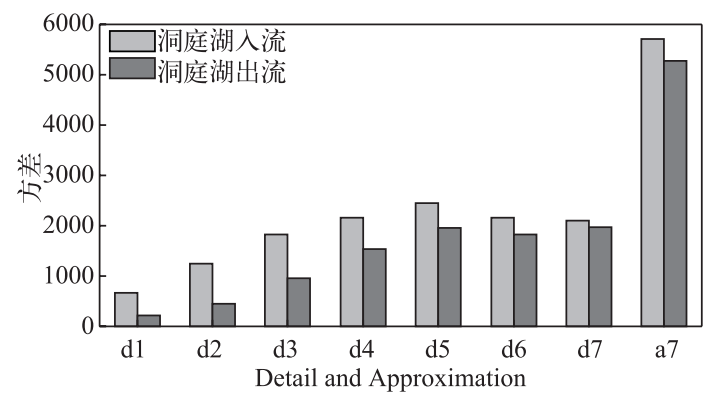

图 3 洞庭湖多年人、出流小波分级各级方差对比

Fig. 3 Standard deviation of wavelets for inflow and outflow in Lake Dongting

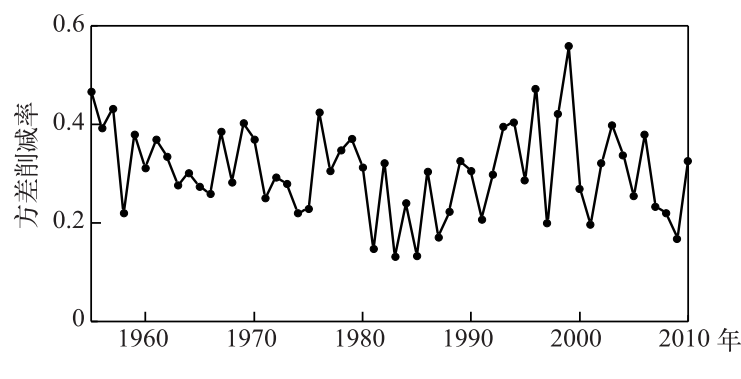

图 4 洞庭湖对短尺度洪水波削峰系数的多年变化

Fig.4 Dynamic of the flood peak removing coefficient in Lake Dongting

表征湖泊调蓄作用的最大调蓄量和洪峰传输时间的长期变化过程显示了与湖泊中短尺度方差和削峰 系数相似的特征. 根据每年最大人湖组合洪峰流量与相应的出湖洪峰流量, 计算洞庭湖历年最大调蓄量 (图 6). 洞庭湖历年最大调蓄量为 $542 \times 10^{8} \sim 31050 \times 10^{8} \mathrm{~m}^{3}$, 多年平均值为 $14580 \times 10^{8} \mathrm{~m}^{3}$. 其历年最大调蓄量无 明显变化趋势, 显示湖泊围垦、泥沙淤积的影响被水位升高所抵消(1996 和 1998 年有破圩的因素, 致使该年 调蓄量偏大). 年内最大调蓄量和出湖径流方差的多年平稳状态可能反映的是城陵矶以下河段过水能力对 洞庭湖的制约. 另外, 洞庭湖平均洪峰传输时间为 $3 \sim 5 \mathrm{~d}$, 历年无显著变化, 说明湖泊形状、面积和容积的变 化对洪峰过程的影响不大.

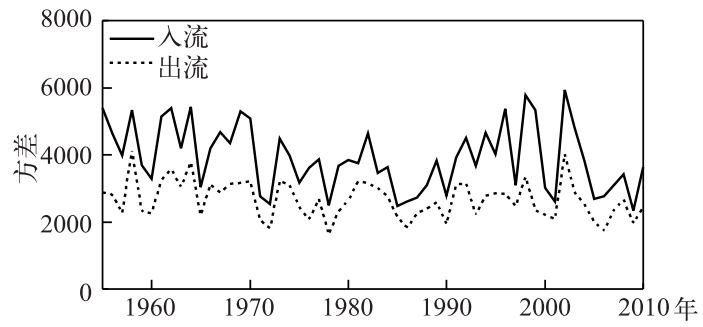

图 5 洞庭湖人、出流中短尺度方差变化

Fig.5 Dynamics of the standard deviation of high frequency wavelets for inflow and outflow in Lake Dongting

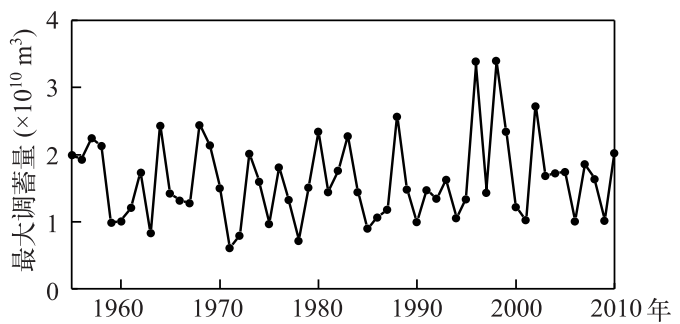

图 6 洞庭湖年最大调蓄量变化 Fig.6 Dynamic of the largest flood regulation volume in Lake Dongting

\section{3 影响洞庭湖调蓄变化的根本原因}

影响湖泊调蓄作用的因素包括人湖洪水形态、湖泊出口水位、泥沙淤积和湖泊围垦. 对于洞庭湖这种过 水性湖泊而言, 需要说明的是: 湖泊调蓄实际上属于河槽调蓄, 调蓄量相当于河槽调蓄量. 首先, 湖泊不同于 分蓄洪区的空库待蓄, 调蓄量是远小于湖泊容积的, 特别是高洪期, 洞庭湖湖容已被前期来水接近充满, 用 于调蓄的湖容大小更多地取决于湖水位的可能涨幅; 其次, 湖泊调蓄不同于水库, 出流是不可控的, 调蓄量 大小取决于湖泊出流顺畅与否, 湖泊出流不畅则洪水更多地滞留湖内,即表现为调蓄作用较强.

从获取的洞庭湖削峰系数 (图 4)、最大调蓄量多年变化过程 (图 6) 及其与洞庭湖面积及容积的变化过 程 (图 7) 可以看出, 两者在变化过程上几乎不存在量变的对应关系. 而与此形成鲜明对比的是城陵矶-螺山 水位落差变化过程 (指示了洞庭湖的出流能力) (图 8) 与洞庭湖短尺度洪水波削峰系数多年过程 (图 4) 在 趋势上呈显著负相关的变化特征, 这种关系表明: 城陵矶一螺山段过流能力是洞庭湖调蓄的决定因素, 即城 
陵矶-螺山段出流顺畅与否决定了洞庭湖调洪削峰能力. 洞庭湖蓄洪多少很大程度上取决于长江干流的水 情, 或者说湖泊的调蓄作用有一部分来自长江干流对湖泊的顶托. 总之, 在整个江湖关系系统中洞庭湖的调 蓄作用的变化是被动的, 近几十年过程中, 江湖关系决定的螺山段泄流能力是影响洞庭湖调蓄能力的核心 要素.

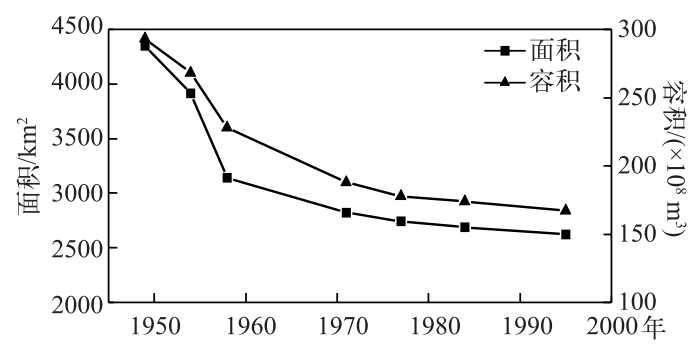

图 7 洞庭湖面积和容积的长期变化

Fig.7 Area and volume evolution of Lake Dongting

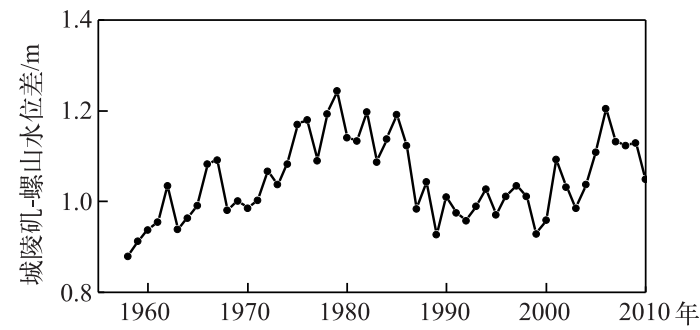

图 8 城陵矶-螺山汛期水位落差变化

Fig.8 Water level difference between Chenglingji-Luoshan

从整个江湖关系下的洞庭湖调蓄变化特征看, 1990s 的“小水大灾”, 总体看径流量不大、水位很高,或洪 峰流量小于历史但水位超历史. 从对洞庭湖人出湖短尺度洪水波方差对比来看, 原因之一是人湖径流量虽 然不大, 但人湖径流过程的短尺度方差较大, 削峰系数更大 (出流不畅导致的出湖径流方差减小), 意味着更 多的洪水滞留湖内. 本质是由于江湖关系导致的长江螺山段出流不畅, 而长江干流出流不畅可以理解为同 水位下流量降低或同流量下水位抬升. 而从近几十年江湖关系变化来看, 水位抬升的主要原因是荆江裁弯 和三峡运行导致的洞庭湖出口下游河段淤积降低了洞庭湖的削峰能力.

另外,在洞庭湖区圩垸中的蓄滞洪垸在作用上类似流域上的调节水库. 这些圩垸虽然极少直接发挥分 蓄洪作用, 但其调蓄洪水效果和提升湖区调蓄能力十分显著. 相比 1954 年洪水, 洞庭湖区分洪和溃口量极 大减少. 1954 年汛期, 长江中下游分洪和溃口总量达 $1023 \times 10^{8} \mathrm{~m}^{3} .1954$ 年以后, 经过 40 多年的堤防加高加 固, 长江中下游的防洪能力大大提高, 加之抗洪抢险成功, 1998 年分洪溃口很少, 全江圩垸的总分洪量仅约 $100 \times 10^{8} \mathrm{~m}^{3}$, 洞庭湖区则更少. 蓄滞洪垸分洪有直接减少断面水量和改变断面水位流量关系两种作用,均可 直接降低洞庭湖水位. 从洞庭湖长期演变来看, 对湖区调蓄洪水将起到越来越重要的作用.

\section{4 结论}

根据洞庭湖调蓄属于典型复合洪水波的实际情况, 利用小波分解和洞庭湖人、出湖方差变化分析了洞 庭湖实际调蓄特征及其演变. 结果显示洞庭湖削减的洪峰主要是 $32 \mathrm{~d}$ 以下的中短尺度洪水波; 洞庭湖对洪 峰的削减作用非常显著, 全年整体削峰系数在 $0.13 \sim 0.56$ 之间. 洞庭湖人、出湖径流方差多年变化平稳, 从 人、出湖径流方差多年变化体现的调蓄效果看, 与洞庭湖面积和容积变化无明显对应关系, 洞庭湖近几十年 淤积围垦并未使湖泊实际调蓄作用 (削峰能力和滞后时间) 发生大的变化.

从洞庭湖削峰系数的多年变化过程来看, 削峰系数与城陵矶-螺山水位落差呈现出的反向变化趋势, 说 明城陵矶-螺山段出流顺畅与否决定了洞庭湖削峰多少, 因此洞庭湖的调蓄主要受控于湖泊出口的过水能 力, 是一种被动调蓄. 1990s 洪峰流量小于历史但水位超历史的 “小水大灾” 原因之一是人湖径流量虽然不 大, 但人湖径流过程的短尺度方差和削峰系数较大, 本质上是由荆江裁弯和三峡运行导致的江湖关系变化 引起的长江螺山段出流使出湖径流方差减小造成的. 鉴于蓄滞洪圩分蓄洪水对减少下游断面水量和改变断 面水位流量关系的直接作用, 其在洞庭湖未来调蓄洪水中将起到越来越重要作用.

\section{5 参考文献}

[ 1 ] Ou CM, Li JB, Zhou YQ et al. Evolution characters of water exchange abilities between Dongting Lake and Yangtze River. 
Journal of Geographical Sciences, 2014, 24(4) : 731-745.

[ 2 ] Yin HF, Liu GR, Pi JG et al. On the river-lake relationship of the middle Yangtze reaches. Geomorphology, 2007, 85(3/ 4) : 197-207.

[ 3 ] 方春明, 钟正琴. 洞庭湖容积减小对洞庭湖和长江洪水位的影响. 水利学报, 2001, (11): 70-74.

[ 4 ] 李景保. 近数十年洞庭湖湖盆形态与水情的变化. 海洋与湖沼, 1992, (6):626-634.

[ 5] 李义天, 邓金运, 孙昭华等. 泥沙淤积与洞庭湖调蓄量变化. 水利学报, 2000, (12): 48-52.

[6] 窦鸿身, 姜加虎. 洞庭湖. 合肥: 中国科学技术大学出版社, 2000.

[ 7 ] 葛守西, 王 俊, 熊 明. 1998 年长江中游干流高水位成因分析. 人民长江, 1999, (2): 30-32.

[8] 李义天, 邓金运, 孙昭华等. 洞庭湖调蓄量变化及其影响因素分析. 泥沙研究, 2001, (6): 1-7.

[9] 姜加虎, 黄 群. 洞庭湖淤积、围星对湖区江湖洪水影响的模拟. 长江流域资源与环境, 2006, (5): 584-587.

[10］赵英林. 洞庭湖洪水地区组成及遭遇分析. 武汉水利电力大学学报, 1997, (1): 38-41.

[11 ] Morlet J, Areans G, Dourgeau E et al. Wave-propagation and sampling theory. 2. Sampling theory and complex waves. Geophysics, 1982, 47(2): 222-236.

[12] 王文圣, 向红莲, 黄伟军等. 基于连续小波变换的径流分维研究. 水利学报, 2005, (5): 598-601. 